\title{
Pharmacological Inhibition of Casein Kinase 2 Enhances the Effectiveness of PI3K Inhibition in Colon Cancer Cells
}

\author{
CRYSTAL SEMAAN $^{1}$, KARLIE A. NEILSON ${ }^{1}$, BENJAMIN BROWN ${ }^{1}$ and MARK P. MOLLOY ${ }^{1,2}$ \\ ${ }^{1}$ Department of Chemistry and Biomolecular Sciences, Macquarie University, Sydney, Australia; \\ ${ }^{2}$ Australian Proteome Analysis Facility, Macquarie University, Sydney, Australia
}

\begin{abstract}
Background/Aim: Serine/threonine kinase B-Raf proto-oncogene (BRAF) mutant colon cancer has a poor prognosis and there is an absence of targeted treatments for this subtype. Here, we investigated the effects of inhibition of casein kinase 2 (CK2) on the inhibitory effects of BRAF and phosphatidylinositol-4,5-bisphosphate 3-kinase (PI3K) inhibition in BRAF-mutant colon cancer cells. Materials and Methods: Colon cancer cell lines with mutations in components of the mitogen-activated protein kinase (MAPK) and PI3K signalling pathway were used. Cell viability was determined after exposure to single agent and combinations of erlotinib (EGFR inhibitor), dabrafenib (MEK inhibitor), GDC0941 (PI3K inhibitor) and CX4945 (CK2 inhibitor). Western blots were used to examine MAPK and AKT serine/threonine kinase (AKT) pathway activation. Results: Addition of CX4945 to dabrafenib did not enhance the antiproliferative effects of single-agent dabrafenib. Use of GDC0941 alone was highly effective in controlling growth of both BRAF-mutant and wild-type cells and this effect was enhanced by CK2 inhibition. Conclusion: Inhibition of the PI3K/AKT pathway is central to regulating growth of colon cancer cells and this can be enhanced by CK2 inhibition.
\end{abstract}

Mutation of the KRAS proto-oncogene (KRAS) gene is commonly associated with the development of colorectal cancer (CRC) through the adenoma-carcinoma sequence, a gradual mutational activation and inactivation of oncogenes and tumour-suppressor genes, respectively. However, approximately $10 \%$ of CRCs are associated with mutation in the serine/threonine kinase $B-R A F$ proto-oncogene $(B R A F)$, which leads to unrestrained signalling through the

Correspondence to: Mark P. Molloy, Bowel Cancer and Biomarker Laboratory, Kolling Institute, The University of Sydney, Sydney, Australia. Tel: +61 299267870, e-mail: m.molloy@sydney.edu.au

Key Words: Colorectal cancer, BRAF, phosphatidyl-inositol-3kinase, casein kinase 2. proliferative mitogen-activated protein kinase (MAPK) pathway in the absence of mitogen ligands. Mutations in $K R A S$ and $B R A F$ are mutually exclusive (1). In the case of melanoma, where $40-60 \%$ of patients harbour the BRAF V600E mutation, specific BRAF drug inhibitors such as vemurafenib and dabrafenib targeting the mutant kinase have been remarkably successful in providing short-term clinical benefit before resistance mechanisms prevail (2-4). Despite this success in combating melanoma, unfortunately in the context of $B R A F$-mutant CRC, clinical testing with the potent BRAF V600E inhibitor vemurafenib (PLX4032) failed to elicit treatment response (5). Subsequent studies to investigate resistance mechanisms demonstrated MAPK reactivation and alternative pro-growth and survival pathways, particularly through epidermal growth factor receptor (EGFR) or phosphatidylinositol-4,5-bisphosphate 3-kinase (PI3K)/AKT serine/threonine kinase (AKT) signalling pathways $(6,7)$. Furthermore, in preclinical models, Mao et al. showed that the vemurafenib analogue PLX4720 combined with the PI3K inhibitor GDC0941 or LY294002 synergistically inhibited proliferation in $B R A F$-mutant colon cancer cell lines (7), underscoring the relevance of these pathways in colon cancer.

Previous work in our laboratory demonstrated that CX4945, a specific inhibitor of casein kinase 2 (CK2), acted in strong synergy to potentiate the inhibitory effects of vemurafenib for treating $B R A F$-mutant melanoma and $B R A F$-mutant thyroid carcinoma cells. We showed that this effect was mediated, in part, through reduced activation of AKT (8). Given the greater reliance of EGFR and $\mathrm{PI} 3 \mathrm{~K} / \mathrm{AKT}$ pathways in CRC compared to melanoma, the focus of this work was to assess whether CK2 inhibition could similarly have a potentiating effect when used in combination with inhibitors targeting these pathways.

\section{Materials and Methods}

Cell culture. Human colon cancer cell lines SW480 (BRAF wildtype, KRASG12V), Colo205 (BRAF V600E) and HT29 (BRAF V600E, PIK3CA P449T) were obtained from American Type 


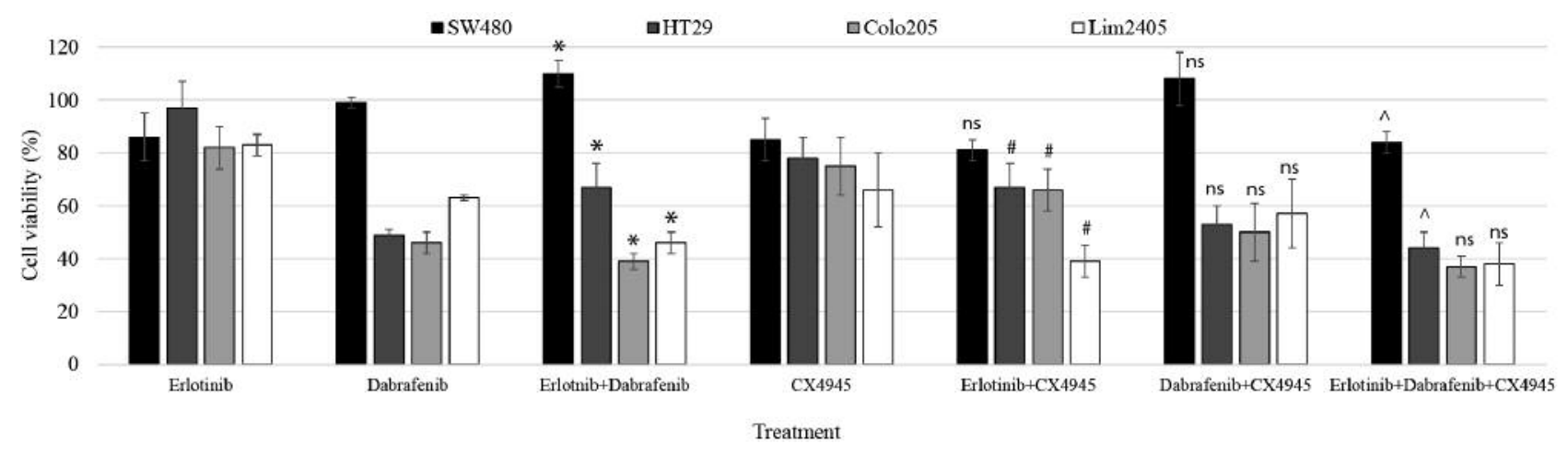

Figure 1. Viability of colon cancer cells following 72-h treatment with epidermal growth factor receptor (EGFR) inhibitor (erlotinib; $2 \mu M$ ), serine/threonine kinase B-Raf proto-oncogene (BRAF) inhibitor (dabrafenib; $15 \mathrm{nM})$, casein kinase $2(C K 2)$ inhibitor $(C X 4945 ; 4 \mu M)$ and combinations thereof $(n=5)$. Data are mean values $\pm S D$. Significantly different at $* p<0.005$ for erlotinib versus erlotinib/darafenib; ${ }^{*} p<0.01$ for erlotinib versus erlotinib/CX4945; ${ }^{\wedge} p<0.005$ for erlotinib/dabrafenib versus erlotinib/dabrafenib/CX4945; ns, not significantly different.

Culture Collection. Lim2405 (BRAF V600E, PTEN-null) were obtained from Professor J. Cebon (Olivia Newton-John Cancer Research Institute, Melbourne, Australia). SW480 and HT29 cells were cultured in Dulbecco's modified Eagle's medium (DMEM) supplemented with $10 \%$ dialysed foetal bovine serum (FBS), $1 \%$ penicillin/streptomycin and $10 \mathrm{mM}$ HEPES. Colo205 and Lim2405 cells were cultured in Roswell Park Memorial Institute medium (RPMI) supplemented with $10 \%$ dialysed FBS, $1 \%$ penicillin/streptomycin, $10 \mathrm{mM}$ HEPES and $10 \mathrm{mM}$ L-glutamine.

Viability assays. The inhibitors erlotinib $(2 \mu \mathrm{M})$, dabrafenib $(15 \mathrm{nM})$, CX4945 (4 $\mu \mathrm{M})$, GDC0941 (4 $\mu \mathrm{M})$ were obtained from Selleckchem, TX, USA. Cells were seeded into 96 -well plates at $5.0 \times 10^{3}$ per well and were allowed to settle for $1 \mathrm{~h}$ in a laminar flow-hood (to reduce edge-effect) before being transferred into an incubator for at least $12 \mathrm{~h}$ before use. Medium was removed and replaced with that containing single drugs or combinations thereof. Dimethyl sulfoxide (DMSO) was used as a control treatment for all drugs. Cells were incubated for $72 \mathrm{~h}$ before being analysed for cell viability using PrestoBlue reagent (ThermoFisher, CA, USA) and read at $570 \mathrm{~nm}$.

Western blot. Cells were seeded into 6-well plates at $5.0 \times 10^{5}$ per well. Cells were allowed to settle for $1 \mathrm{~h}$ in a laminar flow-hood (to reduce edge-effect) before being transferred into an incubator for at least $12 \mathrm{~h}$ before use. The medium was removed and replaced with that containing single drugs or combinations thereof. Cells were incubated for $60 \mathrm{~min}$ before lysis using a buffer consisting of $20 \mathrm{mM}$ Tris- $\mathrm{HCl}$, $150 \mathrm{mM} \mathrm{NaCl}, 1 \mathrm{mM}$ EDTA, $1 \mathrm{mM}$ EGTA, 1\% Triton, pH 7.5. Cell lysate was collected using a cell scraper sonicated on ice for $3 \mathrm{~s}$ at $10 \%$ amplitude.

BCA assay was used to determine protein concentration and $10 \mu \mathrm{g}$ of protein from cells was prepared for $4-12 \%$ Bis-Tris gels run at 200 $\mathrm{V}$ for $1 \mathrm{~h}$. The gel was transferred onto nitrocellulose using a TurboBlot system (BioRad, CA, USA) for $10 \mathrm{~min}$ at $1.5 \mathrm{~V}$. Membranes were washed with Tris-buffered saline (TBS) (1 M Tris$\mathrm{HCl}, 3 \mathrm{M} \mathrm{NaCl}$ ) and blocked in $5 \%$ bovine serum albumin (BSA) in TBS-T (TBS/0.1\% Tween 20). Membranes were then washed with TBS-T and incubated with primary antibody (in 5\% BSA/TBS-T) overnight at $4^{\circ} \mathrm{C}$. Membranes were washed in TBS-T and incubated with secondary antibody for $30 \mathrm{~min}$ at room temperature. Membranes were rinsed in water and imaged using an Odyssey imager (LI-COR Biotechnology, Lincoln, NE, USA) at $700 \mathrm{~nm}$ or $800 \mathrm{~nm}$. Primary antibodies used in this study were: mouse monoclonal anti-ERK1/2 (1:2,000 dilution, Cat \#9107), rabbit polyclonal anti-phospho-ERK1/2 (T202/Y204) (1:1000 dilution, Cat \#9101), rabbit monoclonal antipanAKT $(1: 1,000$ dilution, Cat \# 4691), rabbit monoclonal antiphospho-AKT (S473) (1:1,000 dilution, Cat\# 4060), rabbit monoclonal anti-p70 S6 kinase (1:1,000 dilution, Cat \# 2708), rabbit polyclonal anti-phospho-p70 S6 kinase (T389) (1:1000 dilution, Cat\# 9205) (Cell Signaling Technology, Danvers, MA, USA).

Statistical analysis. Two-tailed, paired Student's $t$-test was performed to evaluate significant changes in cell viability following drug treatments. $p$-Value of less than 0.05 were considered significant.

\section{Results}

CK2 inhibition failed to potentiate the antiproliferative effects of dabrafenib in BRAF-mutant colon cancer cells. We previously observed that inhibition of constitutively active CK2 strongly potentiated the antiproliferative effects of the BRAF inhibitor vemurafenib in melanoma and thyroid cancer cells which carry the $B R A F \mathrm{~V} 600 \mathrm{E} / \mathrm{K}$ mutation (8). Here, we set out to examine whether a similar response could be realized in $B R A F$-mutant colon cancer where monotherapy with BRAF kinase inhibition has been unsuccessful (5). It has been hypothesized that activating mutations within the PI3K pathway in $B R A F$-mutant colon cancer and amplification of EGFR provide sufficient progrowth signalling pathway alternatives to overcome the effectiveness of BRAF blockade (9). For this study, we utilised commonly reported colon cancer cell lines with mutations affecting $B R A F$ and $P I 3 K$ signalling pathways.

As shown in Figure 1, in vitro blocking of EGFR signalling with erlotinib alone was ineffective in reducing 


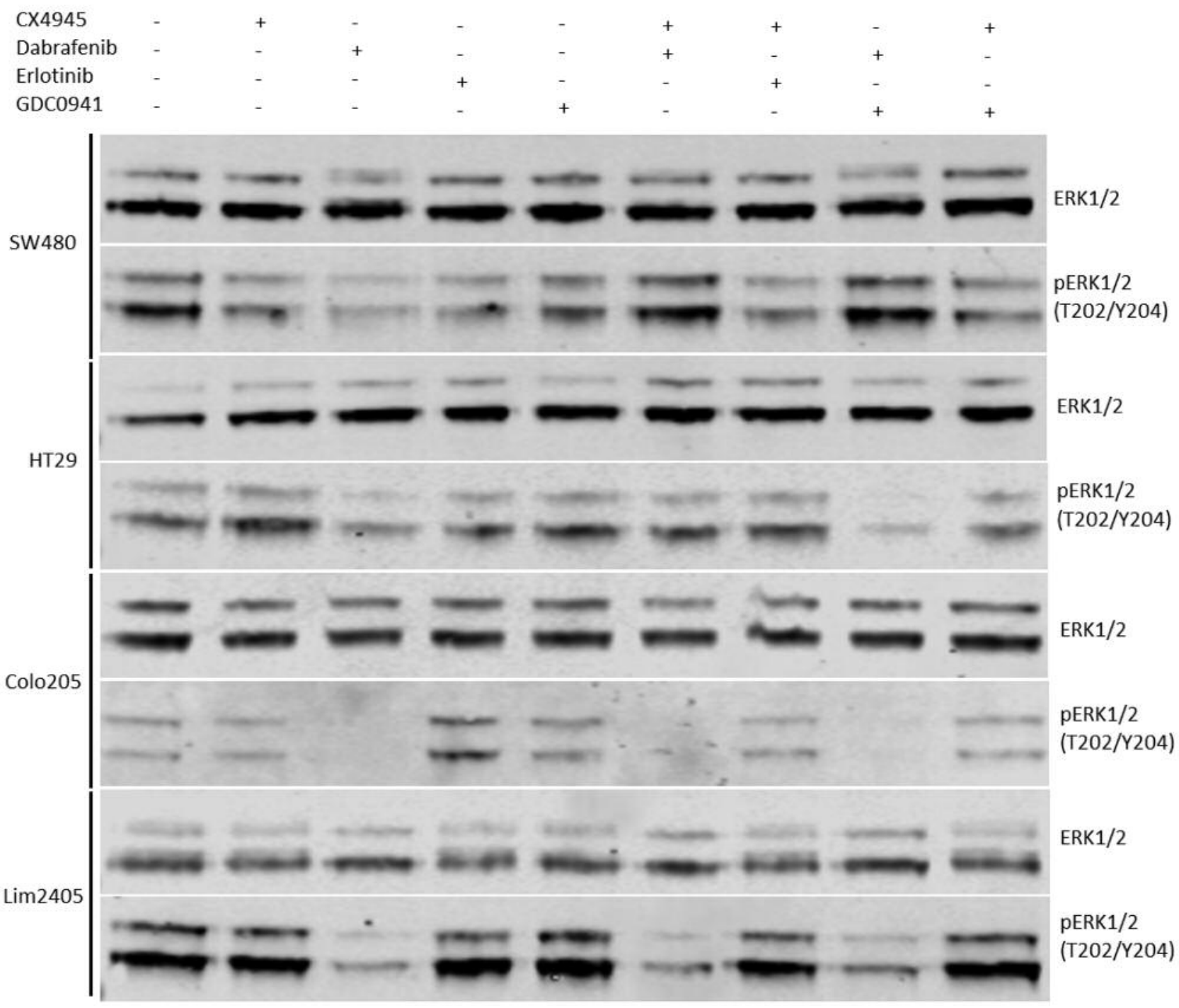

Figure 2. Western blot of extracellular signal-regulated kinase 1/2 (ERK1/2) activation following 1-h treatment with casein kinase 2 (CK2) inhibitor $(C X 4945 ; 4 \mu M)$, serinelthreonine kinase B-Raf proto-oncogene (BRAF) inhibitor (dabrafenib; $15 \mathrm{nM})$, epidermal growth factor receptor (EGFR) inhibitor (erlotinib; $2 \mu M$ ) and combinations thereof $(n=3)$.

cell growth below $80 \%$ of the control in the four colon cancer cell lines after 72-h drug exposure. Treatment with the clinically approved second-generation BRAF inhibitor dabrafenib resulted in reduced cell viability in Colo205 (BRAF V600E) (46\%), HT29 (BRAF V600E and PIK3CA P449T) (49\%) and Lim2405 cells (BRAF V600E/PTEN-null) (10) (63\%), but not BRAF wild-type SW480 cells. The combination of erlotinib and dabrafenib further improved antiproliferative activity in Colo205 and Lim2405 by an additional $\sim 15 \%$ and $\sim 27 \%$ respectively, compared to dabrafenib alone. Paradoxical activation of wild-type $B R A F$ in SW480 cells (KRAS G12V) was observed when erlotinib was combined with dabrafenib, while a similar response was seen in HT29 cells where this dual combination treatment was less effective than dabrafenib alone. Sensitivity to single-agent CK2 inhibition using the drug CX4945 was modest, reducing growth by $66-85 \%$ of controls, similarly to our previous experience for monotherapy in $B R A F$-mutant melanoma and $B R A F$-mutant thyroid cancer cell lines. However, in those cancer types, CK2 inhibition with CX4945 or siRNA knockdown was strongly synergistic in potentiating the antiproliferative effects of BRAF or MEK inhibition (8), but this was not observed here with colon cancer cell lines. Interestingly, use of CK2 inhibitor in 
combination with erlotinib was a useful approach to inhibit cell growth compared to erlotinib monotherapy and in fact was the most successful regimen for slowing proliferation of KRAS-mutant SW480 cells. Triple treatment of erlotinib, dabrafenib and CX4945 added further modest reduction in proliferation to each of the tested models.

We used western blotting of phospho-ERK to monitor MAPK pathway activity after short-term incubation (1 h) with some of these drugs used as monotherapy or in combination (Figure 2). Interestingly, in many cases, but especially with dabrafenib, pERK was reduced with drug treatments, indicating effective pharmacodynamic target inhibition. However, as shown in Figure 1, this did not always translate into effective control of cell proliferation, underscoring the importance of MAPKindependent growth-stimulating pathways in colon cancer cells. For example, dabrafenib and CX4945 strongly inhibited ERK phosphorylation in Colo205 and Lim2405 cells, but not in HT29 cells, while the corresponding viability data showed growth reduction to $50 \%, 57 \%$ and $53 \%$ of controls, respectively.

Controlling activity of PI3K/AKT pathway is effective for $B R A F$-mutant colon cancer and is enhanced by CK2 inhibition. To investigate the contribution of other pathways in driving cell proliferation, we focused on the PI3K/AKT pathway, where components are known to be commonly mutated in CRC. Furthermore, we previously showed that inhibition of CK2 effected reduced priming of AKT through restricting phosphorylation of Ser129 as a likely contributor for its synergistic activity with BRAF inhibition in melanoma and thyroid cells (8). As shown in Figure 2, 1-h treatment with the potent ATP-competitive PI3K $\alpha / \delta$ inhibitor GDC0941 had almost no effect on MAPK activity in these cells, however, we observed potent inhibition of the AKT Ser 473 activation site and subsequent ablation of phosphorylation of the downstream effector p70S6 kinase in each of the four cell lines, consistent with arresting AKT signalling (Figure 3A). We next examined cell proliferation control following 72-h treatment with GDC0941 and this showed cell viability was significantly reduced in all four cell lines (Figure 3B). Interestingly, treatment with $4 \mu \mathrm{M}$ GDC0941 was more effective than $15 \mathrm{nM}$ dabrafenib alone in $B R A F$-mutant cells and was most effective against HT29 cells, which have a constitutively active mutant PI3K enzyme. Furthermore, GDC0941 was the most potent monotherapy trialled for regulating growth in the PTEN-null Lim2405 cell line, reducing growth to $45 \%$ of the control. These observations are consistent with a previous report (7) and confirm the importance of the PI3K pathway in promoting colon cancer cell proliferation. Combination of GDC0941 with dabrafenib predictably reduced growth of HT-29 and Colo205 cells even further, while addition of CX4945 to GDC0941 appeared to be synergistic and produced the surprising effect of greatly reducing growth of $B R A F$ wild-type SW480 cells to less than $40 \%$ of controls.

\section{Discussion}

The absence of effective targeted therapies to treat $B R A F$ mutant colon cancer greatly contrasts the situation observed clinically in $B R A F$-mutant melanoma (5). We previously demonstrated that inhibition of the ubiquitous CK2 strongly potentiates the effect of BRAF and MEK inhibition in $B R A F$ mutant melanoma and $B R A F$-mutant thyroid cancer cells (8) and set out here to evaluate such an approach for $B R A F$ mutant colon cancer. In contrast to our previous findings, we observed no additional benefit of CK2 inhibition when used in combination with dabrafenib, although proliferation was significantly reduced when used in combination with the EGFR blocking drug erlotinib. Furthermore, triple treatment of adding CK2 to erlotinib and dabrafenib was effective for some cell lines and could be further investigated given encouraging outcomes of pilot clinical testing using combinations of EGFR and BRAF inhibition in patients with metastatic BRAF V600E CRC (11).

Colon cancer has a strong reliance on exploiting the progrowth PI3K/AKT signalling pathway and several pre-clinical studies have investigated the use of dual PI3K/mechanistic target of rapamycin (mTOR) and mitogen-activated protein kinase kinase 1/2 (MEK1/2) inhibitors as single agents and in combination therapy in models of human cancer (12-16), although only limited reports have focused specifically on $B R A F$-mutant colon cancer $(6,7)$. Here, it was of interest to determine whether CK2 inhibition could potentiate the effects of PI3K inhibition given we had previously elucidated that CK2 exerts its affects independently on AKT to regulate its priming $(8,17)$, which facilitates subsequent phosphorylation by pyruvate dehydrogenase kinase 1 (PDK1) and mTOR complex-2. Cell viability assays following 3-day exposure to the ATP-competitive PI3K $\alpha / \delta$ inhibitor GDC0941 was highly effective in reducing proliferation in all colon cancer models tested and indeed was more effective than single-agent dabrafenib for -mutant colon cancers. Subsequent addition of CX4945 with GDC0941 successfully potentiated the response in $K R A S$-mutant, $B R A F$-wild-type SW480 cells and $B R A F$ mutant HT29 and Colo205 cells, but not BRAF-mutant/PTENnull Lim2405 cells. Similar observations were seen when GDC0941 was combined with dabrafenib, except in the BRAF wild-type SW480 cells, where this approach activated MAPK signalling through established mechanisms (18).

Clinical testing of controlling the PI3K/AKT signalling axis in BRAF CRC is very limited and our findings further support deeper evaluation of therapeutic targets within this pathway as is being carried out for numerous cancer types (19). van Geel and colleagues recently reported a phase Ib/II study evaluating the RAF inhibitor encorafenib in combination with cetuximab for EGRF blocking, with and without the PI3K $\alpha$ inhibitor alpelisib in BRAF-mutant metastatic CRC (20). The overall response rates were $19 \%$ 
A

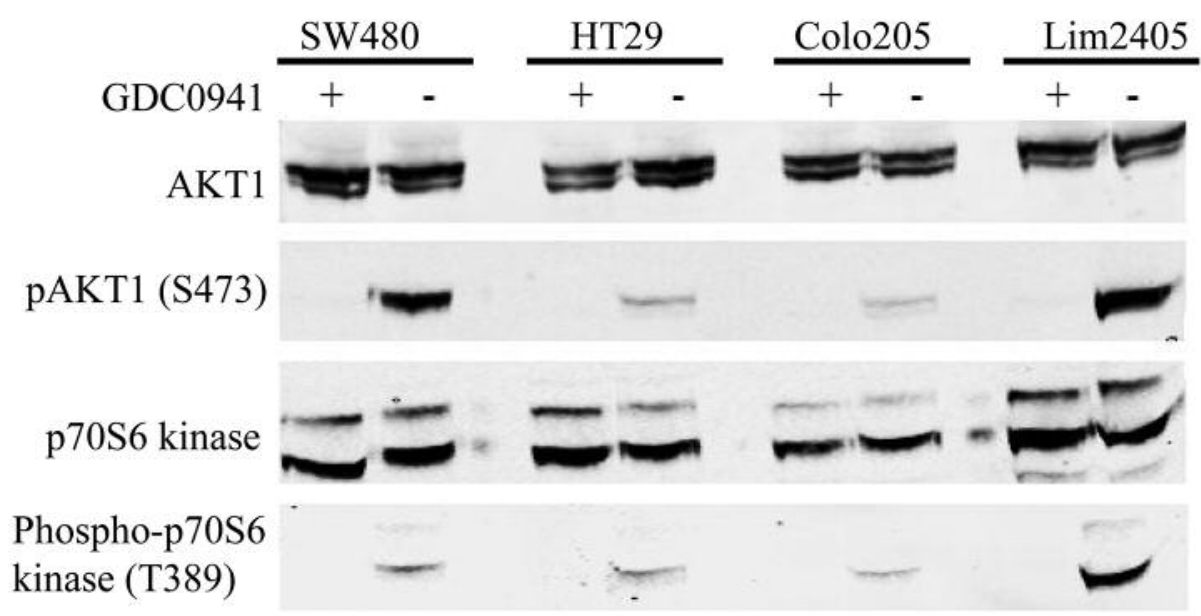

B

- SW480

口HT29

$\square$ Colo205

$\square \operatorname{Lim} 2405$

100

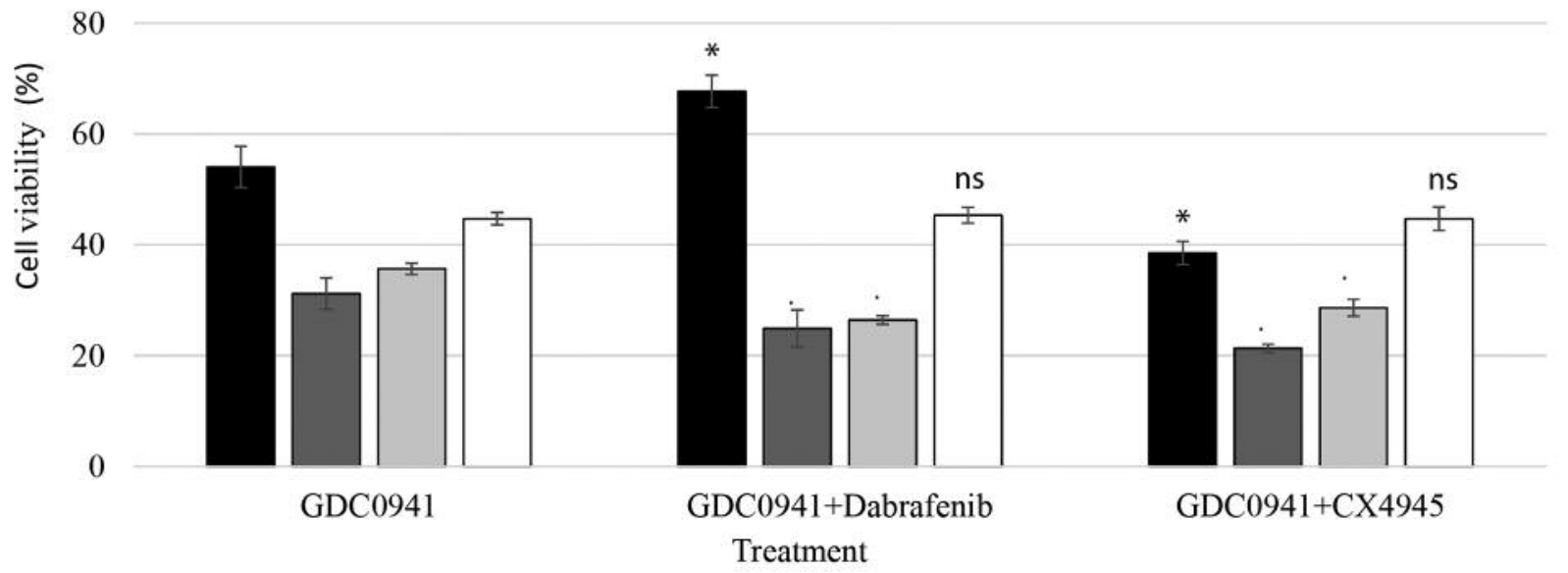

Figure 3. A: Western blot for AKT serine/threonine kinase (AKT) pathway activity following 30-min treatment with phosphatidylinositol-4,5-bisphosphate 3-kinase (PI3K) inhibitor GDC0941 (4 $\mu \mathrm{M})$. B: Cell viability following 72-h exposure to GDC0941, serinelthreonine kinase B-Raf proto-oncogene $(B R A F)$ inhibitor (dabrafenib; $15 \mathrm{nM})$, casein kinase $2(C K 2)$ inhibitor $(C X 4945 ; 4 \mu M)$ and combinations thereof $(n=8)$. Data are mean values $\pm S D$. Significantly different at * $p<0.001$ for GDC0941 versus GDC0941/dabrafenib and GDC0941 versus GDC0941/CX4945; ns, not significantly different.

and $18 \%$ in the two-and three-drug arms, with a median progression-free survival of 3.7 and 4.2 months, respectively. Unfortunately, the maximum tolerated dose was not reached in either arm in this heavily pre-treated cohort and the addition of PI3K inhibitor did not improve overall response rates compared to the doublet combination.

Our investigations showed a role for CK2 inhibition in potentiating the inhibitory effects of GDC0941 in BRAFmutant and wild-type colon cancer cell lines. We found this combination to be superior to targeting MAPK activity using either BRAF or EGFR inhibition, combinations of which have produced modest clinical responses in metastatic BRAF V600E colorectal cancer (21). In vivo studies are now required to further determine efficacy and toxicity associated with $\mathrm{PI} 3 \mathrm{~K} / \mathrm{CK} 2$ combinations for treating colorectal cancer.

\section{Acknowledgements}

MPM acknowledges funding support from Sydney Vital Translational Cancer Research Centre. This research was facilitated by access to the Australian Proteome Analysis Facility through the National Collaborative Research Infrastructure Scheme. 


\section{References}

1 Barras D: BRAF mutation in colorectal cancer: An update. Biomark Cancer 7: 9-12, 2015.

2 Long GV, Stroyakovskiy D, Gogas H, Levchenko E, de Braud F, Larkin J, Garbe C, Jouary T, Hauschild A, Grob JJ, Chiarion Sileni V, Lebbe C, Mandala M, Millward M, Arance A, Bondarenko I, Haanen JB, Hansson J, Utikal J, Ferraresi V, Kovalenko N, Mohr P, Probachai V, Schadendorf D, Nathan P, Robert C, Ribas A, DeMarini DJ, Irani JG, Casey M, Ouellet D, Martin AM, Le N, Patel K and Flaherty K: Combined BRAF and MEK inhibition versus BRAF inhibition alone in melanoma. N Engl J Med 371: 1877-1888, 2014.

3 Solit DB and Rosen N: Resistance to BRAF inhibition in melanomas. N Engl J Med 364: 772-774, 2011.

4 Chapman PB, Hauschild A, Robert C, Haanen JB, Ascierto P, Larkin J, Dummer R, Garbe C, Testori A, Maio M, Hogg D, Lorigan P, Lebbe C, Jouary T, Schadendorf D, Ribas A, O'Day SJ, Sosman JA, Kirkwood JM, Eggermont AM, Dreno B, Nolop K, Li J, Nelson B, Hou J, Lee RJ, Flaherty KT, McArthur GA and Group B-S: Improved survival with vemurafenib in melanoma with $B R A F$ V600E mutation. N Engl J Med 364: 2507-2516, 2011.

5 Prahallad A, Sun C, Huang S, Di Nicolantonio F, Salazar R, Zecchin D, Beijersbergen RL, Bardelli A and Bernards R: Unresponsiveness of colon cancer to $B R A F(\mathrm{~V} 600 \mathrm{E})$ inhibition through feedback activation of EGFR. Nature 483: 100-103, 2012.

6 Coffee EM, Faber AC, Roper J, Sinnamon MJ, Goel G, Keung L, Wang WV, Vecchione L, de Vriendt V, Weinstein BJ, Bronson RT, Tejpar S, Xavier RJ, Engelman JA, Martin ES and Hung KE: Concomitant BRAF and PI3K/mTOR blockade is required for effective treatment of $B R A F(\mathrm{~V} 600 \mathrm{E})$ colorectal cancer. Clin Cancer Res 19: 2688-2698, 2013.

7 Mao M, Tian F, Mariadason JM, Tsao CC, Lemos R, Jr., Dayyani F, Gopal YN, Jiang ZQ, Wistuba, II, Tang XM, Bornman WG, Bollag G, Mills GB, Powis G, Desai J, Gallick GE, Davies MA and Kopetz S: Resistance to BRAF inhibition in $B R A F$-mutant colon cancer can be overcome with PI3K inhibition or demethylating agents. Clin Cancer Res 19: 657-667, 2013.

8 Parker R, Clifton-Bligh R and Molloy MP: Phosphoproteomics of MAPK inhibition in $B R A F$-mutated cells and a role for the lethal synergism of dual BRAF and CK2 inhibition. Mol Cancer Ther 13: 1894-1906, 2014.

9 Corcoran RB, Ebi H, Turke AB, Coffee EM, Nishino M, Cogdill AP, Brown RD, Della Pelle P, Dias-Santagata D, Hung KE, Flaherty KT, Piris A, Wargo JA, Settleman J, Mino-Kenudson M and Engelman JA: EGFR-mediated re-activation of MAPK signaling contributes to insensitivity of $B R A F$-mutant colorectal cancers to RAF inhibition with vemurafenib. Cancer Discov 2: 227-235, 2012.

10 Jhawer M, Goel S, Wilson AJ, Montagna C, Ling YH, Byun DS, Nasser S, Arango D, Shin J, Klampfer L, Augenlicht LH, PerezSoler $\mathrm{R}$ and Mariadason JM: PIK3CA mutation/PTEN expression status predicts response of colon cancer cells to the epidermal growth factor receptor inhibitor cetuximab. Cancer Res 68: 1953-1961, 2008.

11 Yaeger R, Cercek A, O'Reilly EM, Reidy DL, Kemeny N, Wolinsky T, Capanu M, Gollub MJ, Rosen N, Berger MF, Lacouture ME, Vakiani E and Saltz LB: Pilot trial of combined BRAF and EGFR inhibition in BRAF-mutant metastatic colorectal cancer patients. Clin Cancer Res 21: 1313-1320, 2015.
12 Hofmann I, Weiss A, Elain G, Schwaederle M, Sterker D, Romanet V, Schmelzle T, Lai A, Brachmann SM, Bentires-Alj M, Roberts TM, Sellers WR, Hofmann F and Maira SM: $K-R A S$ mutant pancreatic tumors show higher sensitivity to MEK than to PI3K inhibition in vivo. PLoS One 7: e44146, 2012.

13 Roberts PJ, Usary JE, Darr DB, Dillon PM, Pfefferle AD, Whittle MC, Duncan JS, Johnson SM, Combest AJ, Jin J, Zamboni WC, Johnson GL, Perou CM and Sharpless NE: Combined PI3K/mTOR and MEK inhibition provides broad antitumor activity in faithful murine cancer models. Clin Cancer Res 18: 5290-5303, 2012.

14 Engelman JA, Chen L, Tan X, Crosby K, Guimaraes AR, Upadhyay R, Maira M, McNamara K, Perera SA, Song Y, Chirieac LR, Kaur R, Lightbown A, Simendinger J, Li T, Padera RF, Garcia-Echeverria C, Weissleder R, Mahmood U, Cantley LC and Wong KK: Effective use of PI3K and MEK inhibitors to treat mutant Kras G12D and Pik3ca H1047R murine lung cancers. Nat Med 14: 1351-1356, 2008.

15 Kinross KM, Brown DV, Kleinschmidt M, Jackson S, Christensen J, Cullinane C, Hicks RJ, Johnstone RW and McArthur GA: In vivo activity of combined PI3K/mTOR and MEK inhibition in a $\operatorname{Kras}(\mathrm{G} 12 \mathrm{D})$; Pten deletion mouse model of ovarian cancer. Mol Cancer Ther 10: 1440-1449, 2011.

16 Raja M, Zverev M, Seipel K, Williams GT, Clarke AR and Shaw $\mathrm{PH}$ : Assessment of the in vivo activity of PI3K and MEK inhibitors in genetically defined models of colorectal cancer. Mol Cancer Ther 14: 2175-2186, 2015.

17 Di Maira G, Salvi M, Arrigoni G, Marin O, Sarno S, Brustolon F, Pinna LA and Ruzzene M: Protein kinase CK2 phosphorylates and upregulates AKT/PKB. Cell Death Differ 12: 668-677, 2005.

18 Gibney GT, Messina JL, Fedorenko IV, Sondak VK and Smalley KS: Paradoxical oncogenesis - the long-term effects of BRAF inhibition in melanoma. Nat Rev Clin Oncol 10: 390-399, 2013.

19 Janku F: Phosphoinositide 3-kinase (PI3K) pathway inhibitors in solid tumors: From laboratory to patients. Cancer Treat Rev 59: 93-101, 2017.

20 van Geel R, Tabernero J, Elez E, Bendell JC, Spreafico A, Schuler M, Yoshino T, Delord JP, Yamada Y, Lolkema MP, Faris JE, Eskens F, Sharma S, Yaeger R, Lenz HJ, Wainberg ZA, Avsar E, Chatterjee A, Jaeger S, Tan E, Maharry K, Demuth T and Schellens JHM: A phase Ib dose-escalation study of encorafenib and cetuximab with or without alpelisib in metastatic $B R A F$-mutant Colorectal Cancer. Cancer Discov 7: 610-619, 2017.

21 Corcoran RB andre T, Atreya CE, Schellens JHM, Yoshino T, Bendell JC, Hollebecque A, McRee AJ, Siena S, Middleton G, Muro K, Gordon MS, Tabernero J, Yaeger R, O'Dwyer PJ, Humblet Y, De Vos F, Jung AS, Brase JC, Jaeger S, Bettinger S, Mookerjee B, Rangwala F and Van Cutsem E: Combined BRAF, EGFR and MEK inhibition in patients with $B R A F(\mathrm{~V} 600 \mathrm{E})-$ mutant colorectal cancer. Cancer Discov 8: 428-443, 2018.

Received September 18, 2018

Revised October 2, 2018

Accepted October 9, 2018 